\title{
Origin of a major infectious disease in vertebrates: The timing of Cryptosporidium evolution and its hosts
}

\author{
JUAN C. GARCIA-R* and DAVID T. S. HAYMAN \\ Molecular Epidemiology and Public Health Laboratory, Hopkirk Research Institute, Massey University, Private Bag, 11 \\ 222, Palmerston North 4442, New Zealand
}

(Received 10 April 2016; revised 14 Fune 2016; accepted 1 fuly 2016; first published online 30 August 2016)

S U M M A R Y

Protozoan parasites of the genus Cryptosporidium infect all vertebrate groups and display some host specificity in their infections. It is therefore possible to assume that Cryptosporidium parasites evolved intimately aside with vertebrate lineages. Here we propose a scenario of Cryptosporidium-Vertebrata coevolution testing the hypothesis that the origin of Cryptosporidium parasites follows that of the origin of modern vertebrates. We use calibrated molecular clocks and cophylogeny analyses to provide and compare age estimates and patterns of association between these clades. Our study provides strong support for the evolution of parasitism of Cryptosporidium with the rise of the vertebrates about 600 million years ago (Mya). Interestingly, periods of increased diversification in Cryptosporidium coincides with diversification of crown mammalian and avian orders after the Cretaceous-Palaeogene (K-Pg) boundary, suggesting that adaptive radiation to new mammalian and avian hosts triggered the diversification of this parasite lineage. Despite evidence for ongoing host shifts we also found significant correlation between protozoan parasites and vertebrate hosts trees in the cophylogenetic analysis. These results help us to understand the underlying macroevolutionary mechanisms driving evolution in Cryptosporidium and may have important implications for the ecology, dynamics and epidemiology of cryptosporidiosis disease in humans and other animals.

Key words: Coevolution, Cryptosporidium, molecular clock, temporal congruence, Vertebrata.

\section{INTRODUCTION}

Coevolution occurs at many scales and is driven by interactions between species that lead to changes in the evolutionary trajectory of each interacting species. Host-parasite coevolution examples are numerous (algae and virus, Bellec et al. 2014; e.g. pocket gophers and chewing lice, Hafner et al. 1994; insects and fungi, Zhang et al. 2014) and shaped evolutionary theory (Anderson and May, 1982; May and Anderson, 1983). However, unresolved evolutionary histories of several parasitic groups preclude analyses of coevolutionary relationships and the timing of events of the intimate relationship with their hosts.

The evolutionary relationships and time of divergence among major Protozoa groups are contentious (Adl et al. 2007). Although all members of apicomplexans are parasitic and share specific features related to parasitism (e.g. an apical secretory structure mediating locomotion and cellular invasion), its extreme radiation ( $>6000$ species known), adaptation to different niches in higher level eukaryotes (targeted hosts), lack of distinguishable morphological characters, genomic variation and complex life cycles involving multiple stages of infections

* Corresponding author: Molecular Epidemiology and Public Health Laboratory, Hopkirk Research Institute, Massey University, Private Bag, 11 222, Palmerston North 4442, New Zealand. E-mail: j.c.garciaramirez@, massey.ac.nz make it difficult to recover deep evolutionary history and ancestry (Javaux et al. 2001; Templeton et al. 2004; Keeling et al. 2005; Ginger, 2006; Adl et al. 2007; Kuo et al. 2008; Wasmuth et al. 2009; De Baets and Littlewood, 2015). Compelling evidence, however, has progressively emerging and our knowledge of the diversity, origin and evolution of parasitic protists have benefited from molecular methods (Gilabert and Wasmuth, 2013; Sierra et al. 2016).

One of the most important infectious diseases in vertebrates is caused by the Apicomplexa protozoan Cryptosporidium. Different species of this unicellular organism have been found in all living vertebrate groups with some species shared within the same taxonomic Class (e.g. a wide range of mammals including humans, sheep, goats and cattle are the hosts of Cryptosporidium parvum). Species of Cryptosporidium are morphologically indistinguishable and their identification is mainly based on molecular characterization (Xiao et al. 1999; Fayer, 2010). The phylogenetic position has also been debated with the genus placed within the coccidian clade initially, whereas recent molecular studies confirmed a close affinity to the gregarines (Carreno et al. 1999; Barta and Thompson, 2006).

To the best of our knowledge no molecular clock analysis has been applied to establish the timeline of Cryptosporidium evolution and test the congruence of its time of diversification to the origin of major groups of host vertebrates. The evolutionary 
origins and extent of host-parasite interactions can be inferred from time calibrated tree phylogenies. The symmetry in times of divergence between hosts and parasites can provide evidence of coevolution. So, linking results that yield similar dates of divergence from dated trees of host-parasite associations at least hints that a common history of interacting lineages is shared (De Vienne et al. 2013). Here, we use molecular data, a number of calibration points and cophylogeny to compare temporal phylogenies and interactions between Cryptosporidium and their hosts in order to understand the underlying macroevolutionary mechanisms driving evolution of Cryptosporidium diversity. Does the origin of Cryptosporidium follow that of the origin of modern Vertebrata clades?

\section{METHODS}

\section{Taxon sampling}

We assembled a dataset of DNA sequences deposited in GenBank corresponding to $18 \mathrm{~S}$ ribosomal RNA (18S), actin gene (actin) and 70 kilodalton heat shock protein (hsp70). Our sampling includes data from 27 species within the NCBI taxonomy database. Sequence data of additional Apicomplexa species were downloaded from GenBank as a close outgroup. These lineages were from groups closely related to Cryptosporidium (e.g. gregarines, coccidia and hematozoa) and provide appropriate context for dating analyses (Table 1). Sequences of other lineages within Alveolata (Ciliophora) were retrieved and included within the analysis. Rhizaria and Stramenopiles species were used as a known outgroup to all these taxa. We obtained two or more sequences of the same species from different sources when available to minimize systematic errors. After comparison only one sequence for each species was retained for subsequent analysis. A list of specimens and GenBank accession numbers of the sequences included in this study are presented in Table 1.

\section{Phylogenetic analysis}

Alignment of individual datasets was performed with SATé-II program v2.2.7 using MAFFT aligner and MUSCLE merger (Liu et al. 2012). Each gene alignment was checked by eye and further refined by hand prior to phylogenetic analysis. The substitution model was chosen in jModelTest v0·1·1 (Posada, 2008) based on the Akaike Information Criterion (Posada, 2008). Prior to concatenated analyses, single gene datasets were inspected for evidence of significant incongruence by comparing preliminary Maximum Likelihood (ML) trees using RAxML v8·2.4 (Stamatakis et al.
2008; Stamatakis, 2014) and a general time reversible model with gamma distribution $(G T R+\Gamma)$. We observed no significant conflict among individual phylogenies and all subsequent analyses were performed with concatenated data. A 4-way partition by gene strategy was used for the concatenated analysis. The partition scheme was as follow: the fragment of the $18 \mathrm{~S}$ rRNA and first-, second and third-codon position for the protein-coding actin and hsp70 genes. RY-coding at the third codon position was used as a partition strategy. ML analyses were implemented in RAxML using a GTR $+\Gamma$ model with bootstrapping automatically stopped employing the majority rule criterion. Bayesian phylogenetic analyses (BA) were implemented in MrBayes v3·2·6 (Ronquist and Huelsenbeck, 2003; Ronquist et al. 2012) using 10 million generations sampled every 5000th generation, a burn in of $10 \%$, and GTR $+\Gamma+\mathrm{I}$ model of evolution. Convergence and mixing were assessed using Tracer v1.6 (http://tree.bio.ed.ac.uk/software/ tracer/) by examining log-likelihood values across generations and ensuring that post-burn-in samples yielded an effective sample size (ESS) of $>200$ for all parameters. RAxML and MrBayes analyses were performed via the CIPRES portal (Miller et al. 2010). Trees were viewed using FigTree v1·4·2 (http://tree.bio.ed.ac.uk/software/figtree/).

\section{Molecular dating of Cryptosporidium}

Divergence times were estimated in BEAST v1 $8 \cdot 0$ (Drummond and Rambaut, 2007) using the dataset partitioned as for the phylogenetics analyses and an uncorrelated relaxed Bayesian clock with rates among branches distributed according to a lognormal distribution (Drummond et al. 2006). A relaxed clock model can account the variation in substitution rates among lineages (Thorne et al. 1998) while a lognormal distribution accommodates greater flexibility regarding a cladogenetic event (Ho and Phillips, 2009). A Birth-Death process was implemented for the speciation model (Rooney, 2004). The XML file was generated using BEAUti $\mathrm{v} 1 \cdot 8 \cdot 0$ (Drummond et al. 2012) with subsequent modifications by hand. The following dates and calibration priors were used according to mean date estimations in Parfrey et al. (2011). The root prior had a normal distribution of 1365-1577 Mya (95\% range) and Rhizaria a normal distribution of 1017-1256 Mya (95\% range). For comparison, we also used other calibration constraints as found in Parfrey et al. (2011) and Eme et al. (2014). First, a normal distribution of 1110-1315 Mya (95\% range) for the root prior and 816-1016 (95\% range) for the time of the most common ancestor (tmrca) in Rhizaria, secondly, a prior of 1371-1626 Mya (95\% range) and 983-1266 (95\% range) for Rhizaria, according to analysis $(b)$ and $(e)$ in Parfrey et al. 
Table 1. Taxa, major clades, GenBank accession numbers and host range of Cryptosporidium species included in this study

\begin{tabular}{|c|c|c|c|c|c|}
\hline \multirow[b]{2}{*}{ Species } & \multirow[b]{2}{*}{ Major clade } & \multicolumn{3}{|c|}{ GenBank Accession No. } & \multirow[b]{2}{*}{ Host range } \\
\hline & & $18 \mathrm{~S}$ & actin & hsp70 & \\
\hline Cryptosporidium andersoni & Alveolates & KF826312 & & AB610481 & Cattle \\
\hline Cryptosporidium baileyi & & L19068 & AF382346 & KM977645 & Chicken, turkey \\
\hline Cryptosporidium bovis & & JX515546 & AY741307 & AY741306 & Cattle \\
\hline Cryptosporidium canis & & $\mathrm{KC} 445656$ & EU754841 & AY120920 & Dog \\
\hline Cryptosporidium cuniculus & & HQ397716 & GU327783 & KC157562 & Human, rabbit \\
\hline Cryptosporidium erinacei & & KF612324 & KF612326 & KF612325 & Hedgehog \\
\hline Cryptosporidium fayeri & & KP730318 & KP730322 & & Kangaroo \\
\hline Cryptosporidium felis & & KJ194110 & AF382347 & KM977646 & Cat \\
\hline Cryptosporidium fragile & & JX948130 & & & Toad \\
\hline Cryptosporidium galli & & HM116388 & AY163901 & AY168849 & Finch, chicken \\
\hline Cryptosporidium hominis & & DQ286403 & KP314262 & KP314260 & Human \\
\hline Cryptosporidium macropodum & & KP730303 & & & Kangaroo \\
\hline Cryptosporidium meleagridis & & HQ917075 & AF382351 & JX024763 & Turkey \\
\hline Cryptosporidium molnari & & HM243547 & HM365220 & & Gilthead bream, European seabass \\
\hline Cryptosporidium muris & & EU553592 & KJ746834 & KJ746835 & Mouse \\
\hline Cryptosporidium parvum & & AF112569 & M86241 & KC885895 & Human, cattle, sheep, goat \\
\hline Cryptosporidium ryanae & & JN400880 & FJ463206 & EU410346 & Cattle \\
\hline Cryptosporidium scrofarum & & KC481231 & AB852580 & JX424842 & Pig \\
\hline Cryptosporidium serpentis & & EU553553 & AF382353 & AF221541 & Snake, lizard \\
\hline Cryptosporidium struthionis & & AJ697751 & & & Ostrich \\
\hline Cryptosporidium suis & & JQ936502 & EF012372 & DQ898164 & Pig \\
\hline Cryptosporidium tyzzeri & & JX679086 & JQ073414 & & Mouse \\
\hline Cryptosporidium ubiquitum & & KP730300 & HM209377 & HM485436 & Deer \\
\hline Cryptosporidium varanii & & KM870593 & AF382349 & FJ429598 & Green tree monitor, snake \\
\hline Cryptosporidium viatorum & & JX644908 & JN846707 & JX978273 & Human \\
\hline Cryptosporidium wrairi & & AF115378 & AF382348 & AF221536 & Guinea pig \\
\hline Cryptosporidium xiaoi & & KP004203 & GQ337964 & KF907826 & Sheep \\
\hline Ascogregarina taiwanensis & & EF666482 & & & \\
\hline Mattesia geminata & & AY334568 & & & \\
\hline Syncystis mirabilis & & DQ176427 & & & \\
\hline Babesia gibsoni & & KC461261 & & AB248730 & \\
\hline Theileria orientalis & & HM538218 & & & \\
\hline Toxoplasma gondii & & $\mathrm{L} 24381$ & & U85648 & \\
\hline Hammondia hammondi & & AF096498 & & & \\
\hline Hammondia heydorni & & GQ984224 & & DQ997572 & \\
\hline Paramecium tetraurelia & & $\mathrm{AB} 252008$ & & & \\
\hline Chilodonella uncinata & & AF300282 & EU047828 & & \\
\hline Thalassiosira pseudonana & Stramenopiles & HM991698 & & & \\
\hline Phaeodactylum tricornutum & & EF140622 & AY729845 & & \\
\hline Aureococcus anophagefferens & & $\mathrm{U} 40257$ & & & \\
\hline Heterosigma akashiwo & & AB001287 & AY729842 & AY729866 & \\
\hline Apodachlya brachynema & & $\mathrm{AJ} 238663$ & AY729840 & & \\
\hline Bodomorpha minima & Rhizaria & $\mathrm{AF} 411276$ & FJ973394 & & \\
\hline Heteromita globosa & & U42447 & & & \\
\hline Rhizosphaera trigonacantha & & JQ706069 & & & \\
\hline Collophidium ellipsoides & & AB 690557 & & & \\
\hline Acanthostaurus nordgaardi & & HQ651787 & & & \\
\hline
\end{tabular}

(2011), respectively. Divergence estimations based on the CIR clock model with soft- (900-1580 Mya) and hard-bound (1500-1850 Mya) calibration constraints in Eme et al. (2014) were also included. We combined the results of three independent runs of 40 million generations each to ensure ESS were above 200. TreeAnnotator v1·8.0 (Drummond and Rambaut, 2007) was used to combine and summarize trees files, obtain a maximum clade credibility consensus tree, and calculate $95 \%$ credibility intervals. Chains were sampled every 4000th generation and a burn-in of $10 \%$ (4 million generations) was used. Convergence and diagnostics of the Markov process were evaluated by the stability of parameter estimates across generations using Tracer v1.6 (http://tree.bio.ed.ac.uk/software/ tracer/). The tree with the times of divergences and Highest Posterior Density (HPD) intervals was visualized using FigTree v1·4·2 (http://tree.bio.ed. ac.uk/software/figtree/). 


\section{Dating of vertebrate evolution}

The relationships and ages of major clades of vertebrates were based on those estimated by Hedges and Kumar (2009). For comparative analysis we also used molecular timescales for vertebrate evolution as found in Wiens (2015).

\section{Global fit tests}

Global fit analyses and tanglegram visualization were performed on ML tree analyses of Cryptosporidium and their hosts (Table 1). Cytochrome $b$ sequence data were used to generate a $\mathrm{ML}$ tree for the most predominant hosts that have been documented for Cryptosporidium species (Xiao et al. 2002, 2004; Fayer, 2010; Šlapeta, 2013). Distance matrices were calculated using the 'cophenetic' and 'dist.node' commands within the 'ape' package in R (Paradis et al. 2004; R Development Core Team, 2014). A third rectangular matrix was generated for host-parasite links allowing multiple linkages between host and parasite species. We estimated the overall congruence between host and parasite topologies using the patristic distance matrices with the null hypothesis of independent evolution in ParaFit (Legendre et al. 2002). The fit between the Cryptosporidium and host topologies was assessed using the distancebased analysis and a 'cailliez' correction (Cailliez, 1983) with 999 permutations.

RESULTS

\section{Phylogenetic analysis}

The complete alignment of the three gene fragments contained 4653 bp comprising 1850 bp of $18 \mathrm{~S}, 1056$ bp of actin and $1747 \mathrm{bp}$ of hsp70. Bayesian inference yielded a consensus tree that was topologically congruent with the ML tree, with ML bootstrap support and Bayesian posterior probabilities largely consistent among nodes (Fig. 1A and Supplementary Fig. S1). We identified three wellsupported clades for internal groups within Cryptosporidium with similar levels of statistical support from ML and Bayesian analyses (Fig. 1A). The first well-supported split leads to a clade comprising only Cryptosporidium 'struthionis' (clade A), the second clade includes Cryptosporidium galli, Cryptosporidium fragile, Cyptosporidium serpentis, Cryptosporidium andersoni and Cryptosporidium muris (clade B) and a third large clade includes all other species (clade $\mathrm{C}$ ).

\section{Timing of diversification}

Our study showed that the most recent common ancestor of the Cryptosporidium parasite lineage is found near to the Paleozoic/Proterozoic boundary about 590 (877-345) Mya (Fig. 1A) and represents a basal split to the clade composed by $C$. 'struthionis'. The estimated time for the split of the other two major clades within Cryptosporidium occurred during the middle Paleozoic 368 (560-218) Mya, but clade $\mathrm{B}$ lineage formation was around the late Jurassic 162 (291-76) Mya whereas clade C originated during the late Paleozoic 265 (409-153) Mya. Among representatives of Cryptosporidium within clade $\mathrm{C}$ there was evidence of several relatively early lineage-splitting events since the Paleogene (Fig. 1A). Differences in divergence times for the crown Cryptosporidium clade reported from all other analyses are relatively small with estimated times after 400 Mya and before 700 Mya but the width of the $95 \%$ HPD intervals overlapping among interval age estimations (Supplementary Figs S2-S5).

The molecular clock based on an analysis by Hedges and Kumar (2009) showed that the most common ancestor of extant vertebrates is found around 600 Mya. The ages of the Vertebrata origin estimated by Hedges and Kumar (2009) are older than those estimated by Wiens (2015). These time trees differ in the crown age of Vertebrata by about $100 \mathrm{My}$. The phylogeny and time of divergences of the major vertebrate clades is also shown in Fig. $1 \mathrm{~B}$.

\section{Global fit tests}

The cophylogenetic analysis also revealed statistically significant patterns of association between hosts and parasites (Global test: ParaFitGlobal $=1 \cdot 02$, $P$-value $=0.01)$. Comparisons of host and parasite phylogenies based on distance and topology-based analyses provided support for a common macroevolutionary scenario between Cryptosporidium and their vertebrate hosts (Fig. 2).

\section{DISCUSSION}

Our comparison of the divergence times provides evidence for the origin of Cryptosporidium parasites close to the time of the most common ancestor for all vertebrates about 600 Mya. Different calibration points used in this study yield no significant differences for the root of extant Cryptosporidium clade. However, estimated ages for the crown group of Cryptosporidium are older [679 (1012-393) Mya] and younger [408 (703-180) Mya] when a CIR model and hard- and soft-bound is respectively implemented. These times of the origin of Cryptosporidium nevertheless overlap with interval age estimations reported for the origin of Vertebrata (Kumar and Hedges, 1998; Blair and Hedges, 2005; Erwin et al. 2011; Hedges et al. 2015). The basal split between clades $B$ and C about $400 \mathrm{Mya}$ is also congruent with the age of the Actinopterygii clade where fish species that are 


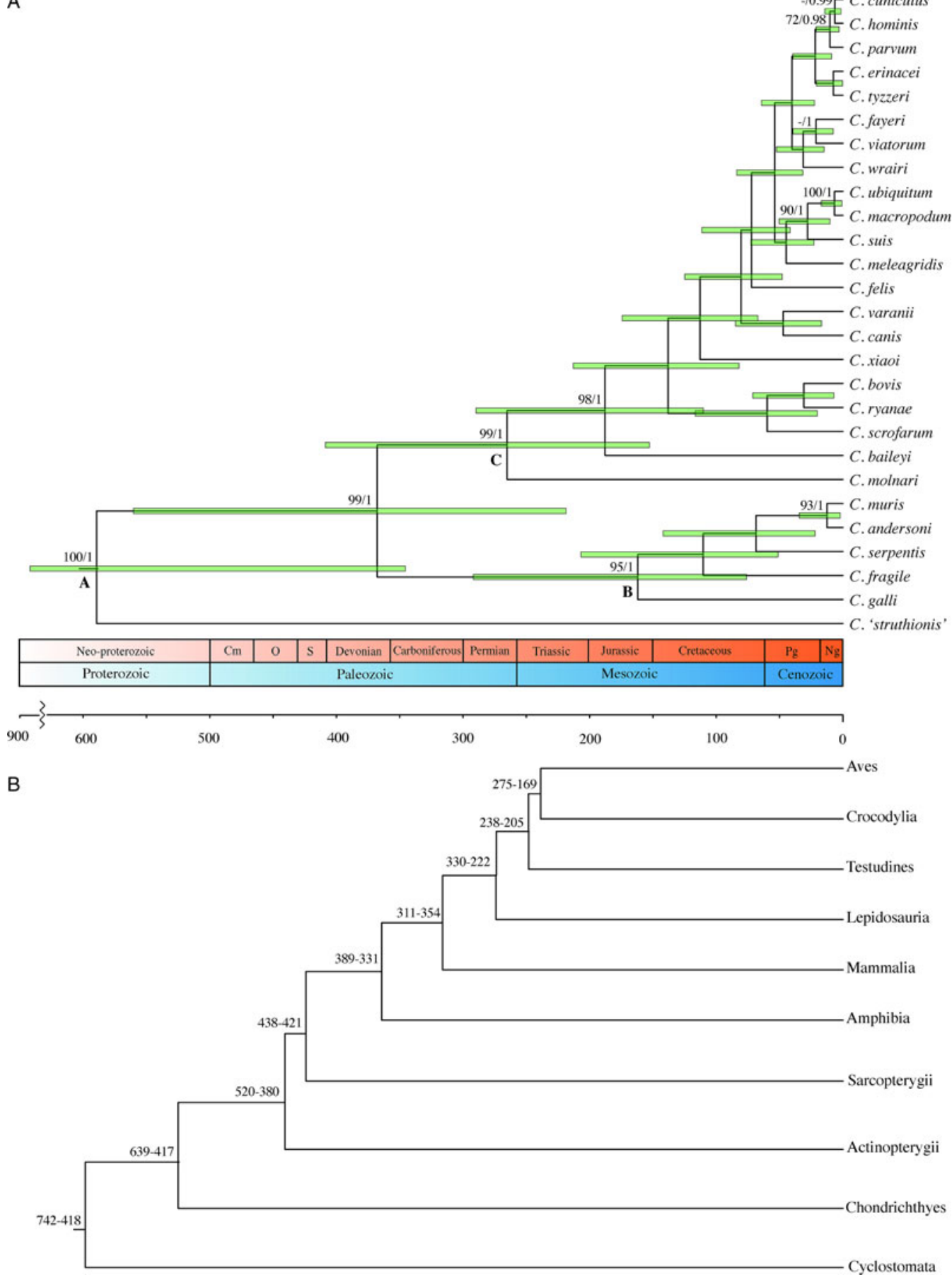

Fig. 1. (A) Chronogram of Cryptosporidium based on concatenated genes (18S, actin and hsp70) with a Lognormal relaxed-clock Bayesian analysis using BEAST. Age constraints were established by a root prior with a normal distribution of 1365-1577 Mya (95\% range) and Rhizaria a normal distribution of 1017-1256 Mya (95\% range). For each node the estimate time of divergence and 95\% Highest Posterior Density (HPD) intervals are shown. The timescale is in millions of years ago (Mya) and geological eras and periods are indicated where Ng (Neogene), Pg (Paleogene), S (Silurian), O (Ordovician) and $\mathrm{Cm}$ (Cambrian). Bootstrap support over 70\% and Bayesian posterior probabilities over 0.9 are found above each branch. Letters below the nodes refer to clades discussed in the text. A complete figure including all species analysed in this study is found in Supplementary Figure S1. (B) A timetree representing temporal patterns of diversification in major lineages of vertebrates. Topology and divergence dates are consensus estimates derived from Hedges and Kumar (2009) and Wiens (2015). Confidence intervals among vertebrate clades are found in each branch following estimates from Blair and Hedges (2005) and Kumar and Hedges (1998). Confidence interval for the origin of Vertebrata includes minimum and maximum age estimations from both studies.

hosts to Cryptosporidium molnari belong to. Analysis of the dated molecular phylogenies suggests that the origin of the clade $\mathrm{C}$, which infects mainly mammalian hosts, is concordant with the age of the stem group of mammals during the Triassic (Close et al. 2015). Yet much of the taxonomic diversity 


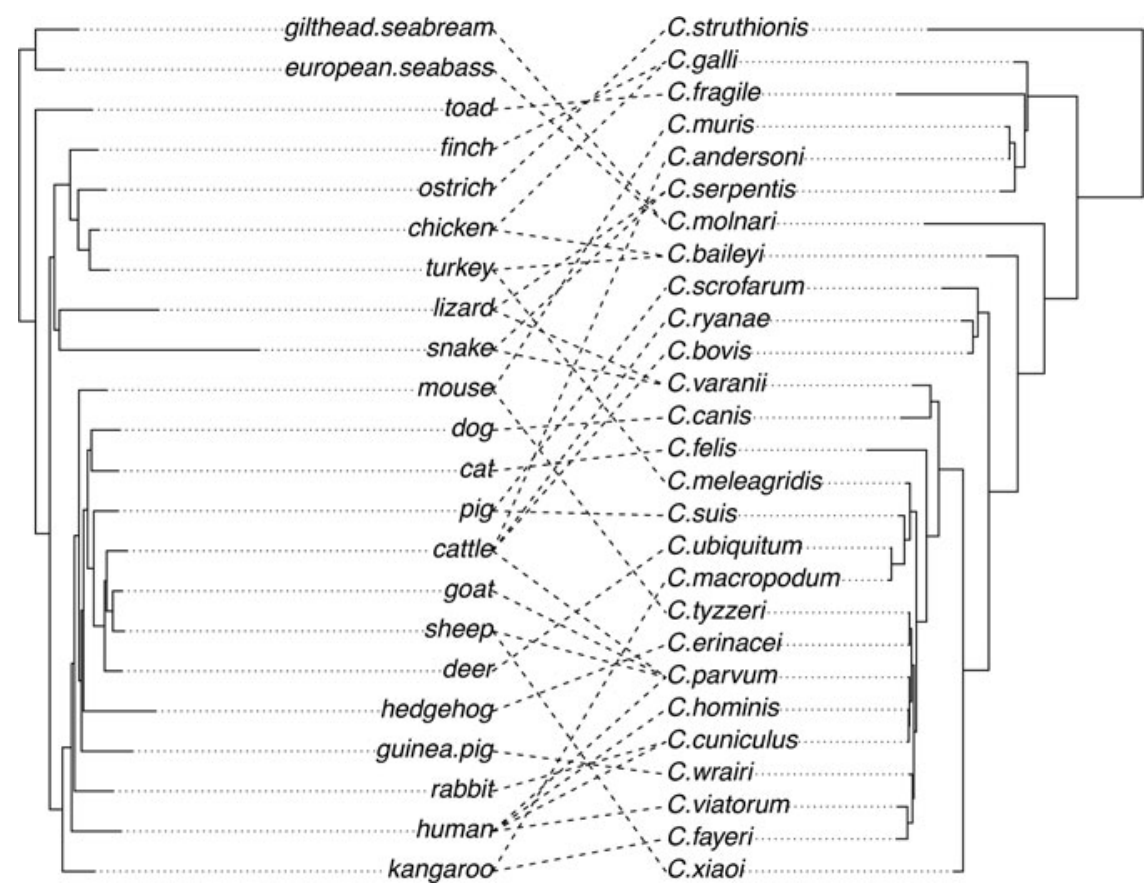

Fig. 2. Tanglegram depicting the host-parasite relationships between Cryptosporidium species (right) and their most dominant vertebrate hosts (left). Phylogenies were reconstructed with Maximum Likelihood (ML) analysis using concatenated data for parasites (18S, actin and hsp70) and a single mtDNA gene (cytb) for hosts.

of Cryptosporidium originated in the Cretaceous, as did most of the terrestrial vertebrates groups (Cooper and Penny, 1997; Kumar and Hedges, 1998). Taxonomic and ecological diversity in Cryptosporidium appears to have evolved during the Cretaceous and provided a launching pad for later diversification during the Tertiary period when mammalian and avian orders diversified after the $\mathrm{K}-\mathrm{Pg}$ event (Dos Reis et al. 2012; O'Leary et al. 2013; Jarvis et al. 2014; Claramunt and Cracraft, 2015; Prum et al. 2015). In this respect the evolution of these parasites mirrors the evolution of vertebrates, primarily in terms of the diversification of terrestrial Eutheria and Metatheria mammals and Palaeognathae and Neognathae birds (e.g. Jetz et al. 2012; Jarvis et al. 2014; Close et al. 2015). Our analyses also find support for the evolution of Cryptosporidium hominis with our human ancestors. The split between C. hominis and C.cuniculus around 6 (1.4-14) Mya suggests an approximate date concordant with our hominini ancestor likely tracing the evolution of $C$. hominis parasite back to that speciation event (Langergraber et al. 2012).

The age congruencies regarding the coevolution of Cryptosporidium and vertebrates from our estimation of divergence times are supported by the global fit test of host-parasite cophylogenetic pattern. The cophylogenetic statistical analysis indicates a predominance of coevolution compared with host shifting despite some parasites infecting multiple hosts. Some Cryptosporidium species seem to be host-restricted to a single host (e.g. C. viatorum has been only found in humans) but others are distributed across different hosts (e.g. C. parvum is found in humans, cattle, sheep, goats) sometimes achieving high prevalence in one or more hosts (Xiao et al. 2002, 2004; Fayer, 2010; Cacciò and Widmer, 2013; Šlapeta, 2013). Cryptosporidium species infecting closely related hosts within some subgroups is especially common within clade C. For instance, C. parvum, C. hominis and C.cuniculus seem to arise owing to movement and specialization to new mammal hosts (e.g. Koehler et al. 2014). These species are not sufficiently specialized to individual hosts to prevent gene flow; therefore it is likely that shifting occurs because there are not ecological barriers for their populations to disperse among different closely related hosts. Such host shifting could be involved in coevolution of resistance factors by the host populations (Ricklefs et al. 2014) but finer resolution analysis, preferably using whole-genome sequences over shorter timescales, are likely required to resolve these parasite-host population level questions.

Host shifting through different host-vertebrate combinations might indicate that the diversity of Cryptosporidium parasites has not been determined yet. Numerous diverse isolates have been characterized probably encompassing more species than those formally described so far (e.g. Alvarez-Pellitero et al. 2004; Li et al. 2015; Ryan et al. 2015). For example, the still undescribed strain Cryptosporidium 'struthionis' has been isolated from ostrich, yet close relatives strains have been found in coprolites of moa (Wood et al. 2013) and free-living in 
tidal-flat (Wilms et al. 2006) and ballast water (Pagenkopp et al. 2016). Cryptosporidium 'struthionis' is on a relatively long branch with seemingly phylogenetically deep origins. This long-branch would probably be broken with additional taxon sampling and sequence data (Bergsten, 2005; Slack et al. 2007). Future taxonomic work will impact our understanding of Cryptosporidium evolution dramatically and will stimulate comparative studies to address the growing number of questions regarding the evolution of protozoan parasites.

\section{SUPPLEMENTARY MATERIAL}

The supplementary material for this article can be found at http://dx.doi.org/10.1017/S0031182016001323.

\section{ACKNOWLEDGEMENTS}

The first author (JCGR) would like to thank to the New Zealand Ministry of Health for support. ${ }^{m}$ EpiLab members provided useful discussions on different stages of the study. We are grateful with two anonymous reviewers for provided helpful comments that improved this manuscript.

\section{FINANCIAL SUPPORT}

This research received no specific grant from any funding agency, commercial or not-for-profit sectors.

\section{REFERENCES}

Adl, S. M., Leander, B. S., Simpson, A. G. B., Archibald, J. M., Anderson, O. R., Bass, D., Bowser, S.S., Brugerolle, G., Farmer, M. A., Karpov, S., Kolisko, M., Lane, C. E., Lodge, D. J., Mann, D. G., Meisterfeld, R., Mendoza, L., Moestrup, Ø., MozleyStandridge, S. E., Smirnov, A. V. and Spiegel, F. (2007). Diversity, nomenclature, and taxonomy of Protists. Systematic Biology 56, 684-689.

Alvarez-Pellitero, P., Quiroga, M. I., Sitja-Bobadilla, A., Redondo, M. J., Palenzuela, O., Vazquez, P. and Nieto, J. M. (2004). Cryptosporidium scophthalmi n. sp. (Apicomplexa: Cryptosporidiidae) from cultured turbot Scophthalmus maximus. Light and electron microscope description and histopathological study. Diseases of Aquatic Organisms 62, 133-145.

Anderson, R. M. and May, R. M. (1982). Coevolution of hosts and parasites. Parasitology 85, 411-426.

Barta, J. R. and Thompson, R. C. A. (2006). What is Cryptosporidium? Reappraising its biology and phylogenetic affinities. Trends in Parasitology 22, 463-468.

Bellec, L., Clerissi, C., Edern, R., Foulon, E., Simon, N., Grimsley, N. and Desdevises, Y. (2014). Cophylogenetic interactions between marine viruses and eukaryotic picophytoplankton. $B M C$ Evolutionary Biology 14, 1-13.

Bergsten, J. (2005). A review of long-branch attraction. Cladistics 21, 163-193. Blair, J. E. and Hedges, S. B. (2005). Molecular phylogeny and divergence times of Deuterostome animals. Molecular Biology and Evolution 22, 2275-2284

Cacciò, S. M. and Widmer, G. (2013). Cryptosporidium: Parasite and Disease. Springer Science \& Business Media, Vienna.

Cailliez, F. (1983). The analytical solution of the additive constant problem. Psychometrika 48, 305-308.

Carreno, R. A., Matrin, D. S. and Barta, J. R. (1999). Cryptosporidium is more closely related to the gregarines than to coccidia as shown by phylogenetic analysis of apicomplexan parasites inferred using small-subunit ribosomal RNA gene sequences. Parasitology Research 85, 899-904.

Claramunt, S. and Cracraft, J. (2015). A new time tree reveals Earth history's imprint on the evolution of modern birds. Science Advances 1, e1501005.
Close, R. A., Friedman, M., Lloyd, G. T. and Benson, R. B. J. (2015). Evidence for a Mid-Jurassic adaptive radiation in mammals. Current Biology 25, 2137-2142.

Cooper, A. and Penny, D. (1997). Mass survival of birds across the Cretaceous-Tertiary boundary: molecular evidence. Science 275, 1109 1113

De Baets, K. and Littlewood, D. T. J. (2015). The importance of fossils in understanding the evolution of parasites and their vectors. In Advances in Parasitology (ed. Kenneth De, B. \& Littlewood, D. T. J.), pp. 1-51. Academic Press, London, UK.

De Vienne, D. M., Refrégier, G., López-Villavicencio, M. Tellier, A., Hood, M. E. and Giraud, T. (2013). Cospeciation vs hostshift speciation: methods for testing, evidence from natural associations and relation to coevolution. New Phytologist 198, 347-385.

Dos Reis, M., Inoue, J., Hasegawa, M., Asher, R. J., Donoghue, P. C. J. and Yang, Z. (2012). Phylogenomic datasets provide both precision and accuracy in estimating the timescale of placental mammal phylogeny. Proceedings of the Royal Society of London B: Biological Sciences 279, 3491-3500.

Drummond, A. J. and Rambaut, A. (2007). BEAST: Bayesian evolutionary analysis by sampling trees. BMC Evolutionary Biology 7, 1-8.

Drummond, A. J., Ho, S.Y.W., Phillips, M. J. and Rambaut, A. (2006). Relaxed phylogenetics and dating with confidence. Plos Biology 4, e88.

Drummond, A. J., Suchard, M. A., Xie, D. and Rambaut, A. (2012). Bayesian phylogenetics with BEAUti and the BEAST 1.7. Molecular Biology and Evolution 29, 1969-1973.

Eme, L., Sharpe, S. C., Brown, M. W. and Roger, A. J. (2014). On the age of Eukaryotes: evaluating evidence from fossils and molecular clocks. In The Origin and Evolution of Eukaryotes (ed. Keeling, P. J. \& Koonin, E. V.), pp. 165-180. Cold Spring Harbor Laboratory Press, New York.

Erwin, D. H., Laflamme, M., Tweedt, S. M., Sperling, E. A., Pisani, D. and Peterson, K. J. (2011). The Cambrian conundrum: early divergence and later ecological success in the early history of animals. Science 334, 1091-1097.

Fayer, R. (2010). Taxonomy and species delimitation in Cryptosporidium. Experimental Parasitology 124, 90-97.

Gilabert, A. and Wasmuth, J. D. (2013). Unravelling parasitic nematode natural history using population genetics. Trends in Parasitology 29, 438-448.

Ginger, M. L. (2006). Niche metabolism in parasitic protozoa. Philosophical Transactions of the Royal Society B: Biological Sciences 361, 101-118.

Hafner, M. S., Sudman, P.D., Villablanca, F.X., Spradling, T. A., Demastes, J. W. and Nadler, S. A. (1994). Disparate rates of molecular evolution in cospeciating hosts and parasites. Science 265, 1087-1090.

Hedges, S. B. and Kumar, S. (2009). The Timetree of Life. Oxford University Press, New York

Hedges, S. B., Marin, J., Suleski, M., Paymer, M. and Kumar, S. (2015). Tree of life reveals clock-like speciation and diversification. Molecular Biology and Evolution 32, 835-845.

Ho, S. Y. W. and Phillips, M. J. (2009). Accounting for calibration uncertainty in phylogenetic estimation of evolutionary divergence times. Systematic Biology 58, 367-380.

Jarvis, E. D., Mirarab, S., Aberer, A. J., Li, B., Houde, P., Li, C., Ho, S. Y. W., Faircloth, B. C., Nabholz, B., Howard, J. T., Suh, A., Weber, C. C., Da Fonseca, R. R., Li, J., Zhang, F., Li, H., Zhou, L., Narula, N., Liu, L., Ganapathy, G., Boussau, B., Bayzid, M. S., Zavidovych, V., Subramanian, S., Gabaldón, T., Capella-Gutiérrez, S., HuertaCepas, J., Rekepalli, B., Munch, K., Schierup, M. et al. (2014). Whole-genome analyses resolve early branches in the tree of life of modern birds. Science 346, 1320-1331.

Javaux, E. J., Knoll, A.H. and Walter, M. R. (2001). Morphological and ecological complexity in early eukaryotic ecosystems. Nature 412, $66-69$.

Jetz, W., Thomas, G. H., Joy, J. B., Hartmann, K. and Mooers, A. O. (2012). The global diversity of birds in space and time. Nature 491, $444-448$.

Keeling, P. J., Burger, G., Durnford, D. G., Lang, B. F., Lee, R. W., Pearlman, R.E., Roger, A. J. and Gray, M.W. (2005). The tree of eukaryotes. Trends in Ecology \& Evolution 20, 670-676.

Koehler, A. V., Whipp, M. J., Haydon, S. R. and Gasser, R. B. (2014). Cryptosporidium cuniculus - new records in human and kangaroo in Australia. Parasites \& Vectors 7, 492

Kumar, S. and Hedges, S. B. (1998). A molecular timescale for vertebrate evolution. Nature 392, 917-920. 
Kuo, C.-H., Wares, J. P. and Kissinger, J. C. (2008). The apicomplexan whole-genome phylogeny: an analysis of incongruence among gene trees. Molecular Biology and Evolution 25, 2689-2698.

Langergraber, K. E., Prüfer, K., Rowney, C., Boesch, C., Crockford, C., Fawcett, K., Inoue, E., Inoue-Muruyama, M., Mitani, J.C., Muller, M.N., Robbins, M.M., Schubert, G., Stoinski, T. S., Viola, B., Watts, D., Wittig, R. M., Wrangham, R. W., Zuberbühler, K., Pääbo, S. and Vigilant, L. (2012). Generation times in wild chimpanzees and gorillas suggest earlier divergence times in great ape and human evolution. Proceedings of the National Academy of Sciences 109, 15716-15721.

Legendre, P., Desdevises, Y. and Bazin, E. (2002). A statistical test for host-parasite coevolution. Systematic Biology 51, 217-234.

Li, X., Pereira, M.D. G. C., Larsen, R., Xiao, C., Phillips, R., Striby, K., Mccowan, B. and Atwill, E. R. (2015). Cryptosporidium rubeyi $\mathrm{n}$. sp. (Apicomplexa: Cryptosporidiidae) in multiple Spermophilus ground squirrel species. International fournal for Parasitology: Parasites and Wildlife 4, 343-350.

Liu, K., Warnow, T. J., Holder, M. T., Nelesen, S. M., Yu, J., Stamatakis, A. P. and Linder, C. R. (2012). SATé-II: very fast and accurate simultaneous estimation of multiple sequence alignments and phylogenetic trees. Systematic Biology 61, 90-106.

May, R. M. and Anderson, R. M. (1983). Epidemiology and genetics in the coevolution of parasites and hosts. Proceedings of the Royal Society of London. Series B, Biological Sciences 219, 281-313.

Miller, M. A., Pfeiffer, W. and Schwartz, T. (2010). Creating the CIPRES Science Gateway for inference of large phylogenetic trees. pp. 1-8. Proceedings of the Gateway Computing Environments Workshop (GCE), New Orleans, LA.

O'leary, M. A., Bloch, J. I., Flynn, J. J., Gaudin, T. J., Giallombardo, A., Giannini, N.P., Goldberg, S. L., Kraatz, B. P., Luo, Z.-X., Meng, J., Ni, X., Novacek, M. J., Perini, F. A., Randall, Z.S., Rougier, G.W., Sargis, E. J., Silcox, M. T., Simmons, N. B., Spaulding, M., Velazco, P. M., Weksler, M., Wible, J. R. and Cirranello, A. L. (2013). The placental mammal ancestor and the post-K-Pg radiation of placentals. Science 339, 662-667. Pagenkopp, K. M., Fleischer, R. C., Carney, K. J., Holzer, K. K. and Ruiz, G. M. (2016). Amplicon-based pyrosequencing reveals high diversity of protistan parasites in ships' ballast water: implications for biogeography and infectious diseases. Microbial Ecology 71, 530-442.

Paradis, E., Claude, J. and Strimmer, K. (2004). APE: analyses of phylogenetics and evolution in R language. Bioinformatics 20, 289-290. Parfrey, L. W., Lahr, D. J. G., Knoll, A. H. and Katz, L. A. (2011) Estimating the timing of early eukaryotic diversification with multigene molecular clocks. Proceedings of the National Academy of Sciences 108, 13624-13629.

Posada, D. (2008). jModelTest: phylogenetic model averaging. Molecular Biology and Evolution 25, 1253-1256.

Prum, R. O., Berv, J. S., Dornburg, A., Field, D. J., Townsend, J. P. Lemmon, E. M. and Lemmon, A. R. (2015). A comprehensive phylogeny of birds (Aves) using targeted next-generation DNA sequencing. Nature 526, 569-573.

R Development Core Team (2014). R: A Language and Environment for Statistical Computing. R Foundation for Statistical Computing, Vienna, Austria.

Ricklefs, R. E., Outlaw, D. C., Svensson-Coelho, M., Medeiros, M. C. I., Ellis, V. A. and Latta, S. (2014). Species formation by host shifting in avian malaria parasites. Proceedings of the National Academy of Sciences 111, 14816-14821.

Ronquist, F. and Huelsenbeck, J. P. (2003). MrBayes 3: Bayesian phylogenetic inference under mixed models. Bioinformatics 19, 1572-1574. Ronquist, F., Teslenko, M., Van Der Mark, P., Ayres, D. L., Darling, A., Höhna, S., Larget, B., Liu, L., Suchard, M. A. and
Huelsenbeck, J. P. (2012). MrBayes 3·2: efficient Bayesian phylogenetic inference and model choice across a large model space. Systematic Biology 61, 539-542.

Rooney, A. P. (2004). Mechanisms underlying the evolution and maintenance of functionally heterogeneous $18 \mathrm{~S}$ rRNA genes in Apicomplexans. Molecular Biology and Evolution 21, 1704-1711.

Ryan, U., Paparini, A., Tong, K., Yang, R., Gibson-Kueh, S., O'hara, A., Lymbery, A. and Xiao, L. (2015). Cryptosporidium huwi n. sp. (Apicomplexa: Eimeriidae) from the guppy (Poecilia reticulata). Experimental Parasitology 150, 31-35.

Sierra, R., Cañas-Duarte, S. J., Burki, F., Schwelm, A., Fogelqvist, J., Dixelius, C., González-García, L. N., Gile, G. H., Slamovits, C. H., Klopp, C., Restrepo, S., Arzul, I. and Pawlowski, J. (2016) Evolutionary origins of Rhizarian parasites. Molecular Biology and Evolution 33, 980-983

Slack, K. E., Delsuc, F., Mclenachan, P. A., Arnason, U. and Penny, D. (2007). Resolving the root of the avian mitogenomic tree by breaking up long branches. Molecular Phylogenetics and Evolution 42, 1-13. Šlapeta, J. (2013). Cryptosporidiosis and Cryptosporidium species in animals and humans: a thirty colour rainbow? International fournal for Parasitology 43, 957-970.

Stamatakis, A. (2014). RAxML version 8: a tool for phylogenetic analysis and post-analysis of large phylogenies. Bioinformatics 30, 1312-1313.

Stamatakis, A., Hoover, P. and Rougemont, J. (2008). A rapid bootstrap algorithm for the RAxML web servers. Systematic Biology 57, 758-771.

Templeton, T.J., Iyer, L. M., Anantharaman, V., Enomoto, S., Abrahante, J.E., Subramanian, G. M., Hoffman, S. L., Abrahamsen, M. S. and Aravind, L. (2004). Comparative analysis of Apicomplexa and genomic diversity in Eukaryotes. Genome Research 14, 1686-1695.

Thorne, J. L., Kishino, H. and Painter, I. S. (1998). Estimating the rate of evolution of the rate of molecular evolution. Molecular Biology and Evolution 15, 1647-1657.

Wasmuth, J., Daub, J., Peregrín-Alvarez, J. M., Finney, C. a. M. and Parkinson, J. (2009). The origins of apicomplexan sequence innovation. Genome Research 19, 1202-1213.

Wiens, J. J. (2015). Explaining large-scale patterns of vertebrate diversity. Biology Letters 11, 1-4.

Wilms, R., Sass, H., Köpke, B., Köster, J., Cypionka, H. and Engelen, B. (2006). Specific bacterial, archaeal, and Eukaryotic communities in tidal-flat sediments along a vertical profile of several meters. Applied and Environmental Microbiology 72, 2756-2764.

Wood, J. R., Wilmshurst, J. M., Rawlence, N. J., Bonner, K. I., Worthy, T. H., Kinsella, J. M. and Cooper, A. (2013). A megafauna's microfauna: Gastrointestinal parasites of New Zealand's extinct moa (Aves: Dinornithiformes). PLoS ONE 8, e57315.

Xiao, L., Escalante, L., Yang, C., Sulaiman, I., Escalante, A. A., Montali, R. J., Fayer, R. and Lal, A. A. (1999). Phylogenetic analysis of Cryptosporidium parasites based on the small-subunit rRNA gene locus. Applied and Environmental Microbiology 65, 1578-1583.

Xiao, L., Sulaiman, I. M., Ryan, U.M., Zhou, L., Atwill, E. R., Tischler, M. L., Zhang, X., Fayer, R. and Lal, A. A. (2002). Host adaptation and host-parasite co-evolution in Cryptosporidium: implications for taxonomy and public health. International fournal for Parasitology 32, $1773-1785$.

Xiao, L., Fayer, R., Ryan, U. and Upton, S. J. (2004). Cryptosporidium taxonomy: recent advances and implications for public health. Clinical Microbiology Reviews 17, 72-97.

Zhang, Y., Zhang, S., Li, Y., Ma, S., Wang, C., Xiang, M., Liu, X., An, Z., Xu, J. and Liu, X. (2014). Phylogeography and evolution of a fungal-insect association on the Tibetan Plateau. Molecular Ecology 23, $5337-5355$. 